\title{
Spontaneous iliopsoas muscle hematoma mimicking avascular necrosis in alcoholic liver cirrhosis: a case report
}

\author{
Hee Yeon Kim^, Hyo-Jin Lee \\ Department of Internal Medicine, Uijeongbu St. Mary's Hospital, College of Medicine, the Catholic University of Korea, Gyeonggi-do, Republic of \\ Korea \\ Correspondence to: Hyo-Jin Lee, MD, PhD. Department of Internal Medicine, Uijeongbu St. Mary's Hospital, College of Medicine, the Catholic \\ University of Korea, 271, Cheonbo-Ro, Uijeongbu-si, Gyeonggi-do, 11765, Republic of Korea. Email: happyjinns@hanmail.net.
}

\begin{abstract}
Spontaneous hematoma of the iliopsoas muscle is rare but may cause limitation of hip flexion and functional inability of the affected limb, mimicking avascular necrosis of the femoral head in patients with alcoholic liver cirrhosis. We report a rare case of spontaneous iliopsoas hematoma that caused a positive Patrick's sign and mimicked avascular necrosis in a patient with alcoholic liver cirrhosis. A 35-year-old female presented with left inguinal pain and limitation of motion. She had a history of alcoholic liver cirrhosis. On physical examination, Patrick's sign was positive, suggestive of hip joint pathology. The Child-Pugh score was 9 and an acute decline in hemoglobin level was noted. Computed tomography scan of the abdomen indicated a 20-cm-sized hematoma along the left iliopsoas muscle. Because the patient's liver function was poor and there was no evidence of active bleeding from the iliopsoas muscle, a conservative treatment option was taken. On follow-up computed tomography one month later, the size of the hematoma decreased to $3.3 \mathrm{~cm}$. Although avascular necrosis occurs frequently in patients with chronic alcohol intake, clinicians should be aware of iliopsoas muscle hematoma mimicking avascular necrosis as a clinically important bleeding complication of alcoholic liver cirrhosis patients to avoid delays in diagnosis and treatment.
\end{abstract}

Keywords: Avascular necrosis (AVN); case report; liver cirrhosis (LC); muscle hematoma; iliopsoas

Submitted Aug 17, 2021. Accepted for publication Oct 29, 2021.

doi: 10.21037/apm-21-2299

View this article at: https://dx.doi.org/10.21037/apm-21-2299

\section{Introduction}

Iliopsoas muscle hematoma mostly occurs in patients with clotting difficulties either spontaneously or secondary to trauma, and it is a rare lesion in patients with liver cirrhosis (LC) (1-3). Clinical signs and symptoms of iliopsoas muscle hematoma include groin pain or swelling and pelvic, back, or lower abdominal pain. Muscle hematoma may cause limitation of hip flexion and functional inability of the affected limb, mimicking avascular necrosis (AVN) of the femoral head of which patients with long term alcohol intake have an increased risk (4). Herein, we present a case of spontaneous iliopsoas hematoma mimicking AVN, suggested by a positive Patrick's test, in a patient with alcoholic LC. We present the following case in accordance with the CARE reporting checklist (available at https://apm. amegroups.com/article/view/10.21037/apm-21-2299/rc).

\section{Case presentation}

A 35-year-old woman visited our emergency department suffering from left inguinal pain and limitation of motion which started two days previously. She had a one-year history of alcoholic LC. She consumed at least $80 \mathrm{~g}$ of alcohol per day for 10 years. She denied any history of recent trauma. She also denied any history of melena. Her blood pressure

$\wedge$ ORCID: 0000-0002-9663-132X. 


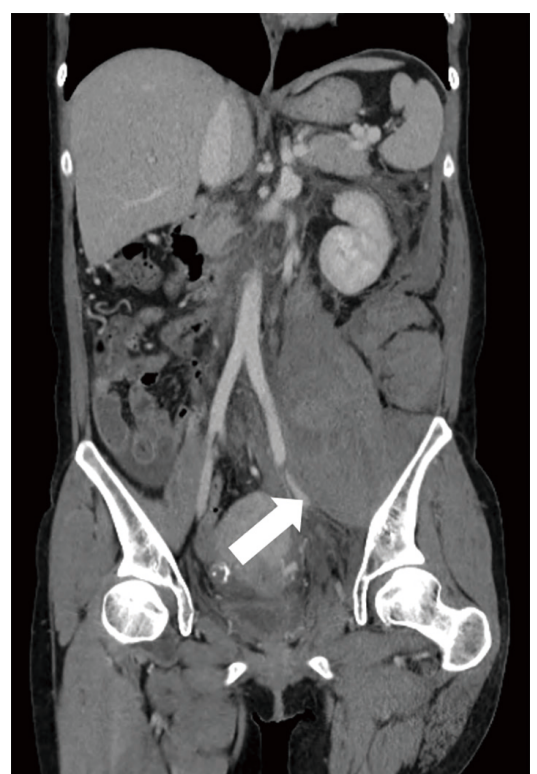

Figure 1 A CT scan of the abdomen indicates a 20-cm-sized hematoma (arrow) along the left iliopsoas muscle without extravasation of contrast medium. CT, computed tomography.

was $110 / 60 \mathrm{mmHg}$ with a pulse rate of 102 beats per minute and a body temperature of $38.1^{\circ} \mathrm{C}$. Physical examination indicated tenderness in the left lower abdomen and left inguinal area. Hip flexion was $4 / 5$ in the left lower limb and $5 / 5$ in the right lower limb. Patrick's test of the left hip was positive. Motor and sensory tests of the left lower limb were normal. Considering the positive Patrick's test and history of chronic alcohol consumption, we suspected avascular necrosis of the femoral head. Laboratory tests disclosed the following: white blood cell count, $14,460 / \mu \mathrm{L}$ with $63.9 \%$ neutrophils; hemoglobin, $6.0 \mathrm{~g} / \mathrm{dL}$; platelets, $110,000 / \mu \mathrm{L}$; total bilirubin, $7.9 \mathrm{mg} / \mathrm{dL}$; aspartate aminotransferase, $103 \mathrm{U} / \mathrm{L}$; alanine aminotransferase, $40 \mathrm{U} / \mathrm{L}$; alkaline phosphatase, $209 \mathrm{U} / \mathrm{L}$; gamma-glutamyl transferase, $35 \mathrm{U} / \mathrm{L}$; and albumin, $2.4 \mathrm{~g} / \mathrm{dL}$. The coagulation profile showed prothrombin time of $49.2 \%$ and international normalized ratio of 1.64 . The C-reactive protein level was $0.97 \mathrm{mg} / \mathrm{dL}$ (normal range $<0.3 \mathrm{mg} / \mathrm{dL}$ ). The Child-Pugh score was 9 (grade B) and the Maddrey's discriminant function score was 31.8. The corticosteroid treatment was not indicated considering the severity of the alcoholic hepatitis.

Given acute anemia, lack of melena, and the presence of abdominal pain, a computed tomography (CT) of the abdomen was performed to rule out intraabdominal hemorrhage. A CT image of the abdomen demonstrated

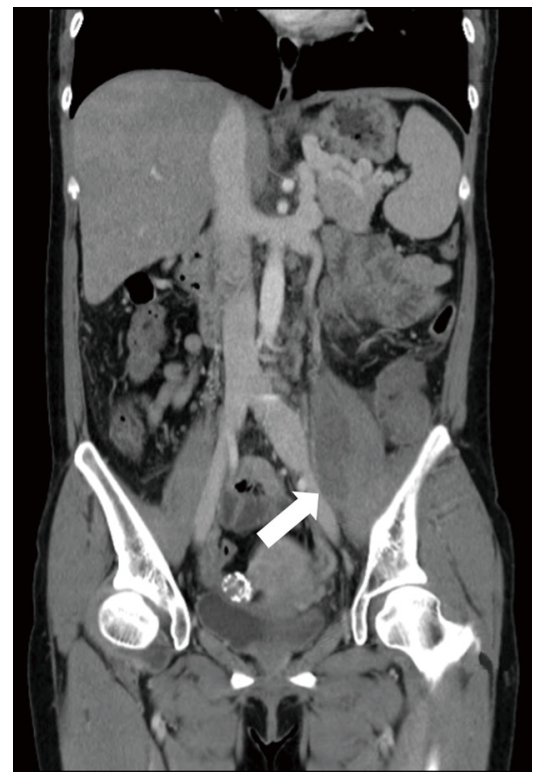

Figure 2 A CT scan of the abdomen one month after conservative treatment showed regression of the left iliopsoas muscle hematoma (arrow). CT, computed tomography.

a 20-cm-sized hematoma along the left iliopsoas muscle without extravasation of contrast medium (Figure 1). For spontaneous resorption of the hematoma, the patient received conservative treatment including rest, antibiotics, and infusions of vitamin $\mathrm{K}$, tranexamic acid, fresh frozen plasma and packed red blood cells. After the patient received 2 units of packed red blood cells, her hemoglobin elevated to $8.7 \mathrm{~g} / \mathrm{dL}$ with no further drop, suggestive of no further bleeding. During the patient's hospital stay, her overall condition and liver function continued to improve. On the 9th day of admission, a follow-up CT revealed reduction of the hematoma of the iliopsoas muscle. The patient was discharged 10 days after admission with pain free walking and normal range of motion of the left hip. She was advised to stop alcohol consumption after discharge. A CT scan obtained 1 month after diagnosis indicated regression of the hematoma to $3.3 \mathrm{~cm}$ in diameter (Figure 2).

All procedures performed in this study were in accordance with the ethical standards of the institutional and/or national research committee(s) and with the Helsinki Declaration (as revised in 2013). Written informed consent was obtained from the patient for publication of this case report and accompanying images. A copy of the written consent is available for review by the editorial office of this journal. 


\section{Discussion}

Spontaneous muscle hematoma usually occurs in patients receiving anticoagulant therapy or those with hemophilia, whereas it is rarely reported in patients with LC (1-3). The most common cause of liver cirrhosis in reported cases with spontaneous muscle hematoma was alcohol abuse, and the patients had a poor prognosis (3). Our patient was diagnosed with a hematoma of the left iliopsoas muscle secondary to alcoholic liver cirrhosis. It appears that LC coupled with active alcohol consumption additively increase the risk for spontaneous muscle bleeding. Several possible explanations for the increased hemorrhagic tendencies in LC include thrombocytopenia, platelet dysfunction, decreased levels of coagulation factors, and hyperfibrinolysis (5). Due to the increased risk of bleeding in LC, rare but lethal spontaneous bleeding emergencies had been reported in patients with LC $(6,7)$. Alcohol abuse, by itself, contributes to dysfunctional coagulation by causing blood vessel wall fragility and inhibition of platelet aggregation and adhesion (8).

Frequently reported symptoms of an iliopsoas hematoma include acute groin pain, femoral neuropathy, general fatigue, and low back pain (9). The present patient complained of inguinal-area pain and gait disturbance. Physical examination of our patient revealed groin pain while applying Patrick's test, suggestive of a hip joint disorder on the ipsilateral side. Because alcohol consumption is the most common etiology for AVN of the femoral head in adults (10), we initially suspected AVN of the femoral head. However, an abdominal CT scan was conducted due to an acute drop in the hemoglobin to $6.0 \mathrm{~g} / \mathrm{dL}$, lack of evidence of gastrointestinal bleeding, and the presence of left lower abdominal pain in our patient. The CT scan allowed rapid diagnosis of the underlying liver disease and delineated the muscle hematoma. Typically, the considerable difficulties in the suspicion of iliopsoas muscle hematoma often lead to unnecessary examinations or a delay in diagnosis.

There is no established treatment for iliopsoas muscle hematoma in LC. Treatment options include conservative care, transcatheter arterial embolization, or surgical removal. Treatment of iliopsoas muscle hematoma complicating LC is challenging considering patients' hemostatic dysfunction and poor general health status. Nonsurgical management is suggested in the absence of gradual dysfunction of the femoral nerve or compression of the surrounding crucial tissues (11). In our case, we selected conservative therapy due to the high surgical risk associated with liver cirrhosis and no evidence of active bleeding or neurological dysfunction. Our patient successfully responded to transfusion of blood products and infusion of vitamin $\mathrm{K}$ and tranexamic acid.

The reported mortality rate of muscle hematoma in LC patients is high $(3,9)$. It is important to suspect a rare spontaneous muscle hematoma to make an early diagnosis and apply the timely treatment in LC patients, thereby improving their prognosis. In conclusion, clinicians should be aware of iliopsoas muscle hematoma mimicking avascular necrosis of the femoral head on physical examination as an uncommon but clinically important bleeding complication of alcoholic LC patients.

\section{Acknowledgments}

Funding: None.

\section{Footnote}

Reporting Checklist: The authors have completed the CARE reporting checklist. Available at https://apm.amegroups. com/article/view/10.21037/apm-21-2299/rc

Peer Review File: Available at https://apm.amegroups.com/ article/view/10.21037/apm-21-2299/prf

Conflicts of Interest: Both authors have completed the ICMJE uniform disclosure form (available at https://apm. amegroups.com/article/view/10.21037/apm-21-2299/coif). The authors have no conflicts of interest to declare.

Ethical Statement: The authors are accountable for all aspects of the work in ensuring that questions related to the accuracy or integrity of any part of the work are appropriately investigated and resolved. All procedures performed in this study were in accordance with the ethical standards of the institutional and/or national research committee(s) and with the Helsinki Declaration (as revised in 2013). Written informed consent was obtained from the patient for publication of this case report and accompanying images. A copy of the written consent is available for review by the editorial office of this journal.

Open Access Statement: This is an Open Access article distributed in accordance with the Creative Commons Attribution-NonCommercial-NoDerivs 4.0 International 
License (CC BY-NC-ND 4.0), which permits the noncommercial replication and distribution of the article with the strict proviso that no changes or edits are made and the original work is properly cited (including links to both the formal publication through the relevant DOI and the license). See: https://creativecommons.org/licenses/by-nc-nd/4.0/.

\section{References}

1. Rodriguez-Merchan EC, De la Corte-Rodriguez H. Iliopsoas hematomas in people with hemophilia: diagnosis and treatment. Expert Rev Hematol 2020;13:803-9.

2. Sasson Z, Mangat I, Peckham KA. Spontaneous iliopsoas hematoma in patients with unstable coronary syndromes receiving intravenous heparin in therapeutic doses. Can J Cardiol 1996;12:490-4.

3. Takamura M, Watanabe J, Sakamaki A, et al. Alcoholic liver disease complicated by deep bleeding into the muscles or retroperitoneum: report of three cases and a review of the literature. Intern Med 2014;53:1763-8.

4. Ponzio DY, Pitta M, Carroll KM, et al. Hip arthroplasty

Cite this article as: Kim HY, Lee HJ. Spontaneous iliopsoas muscle hematoma mimicking avascular necrosis in alcoholic liver cirrhosis: a case report. Ann Palliat Med 2022;11(7):2544-2547. doi: 10.21037/apm-21-2299 for osteonecrosis of the femoral head secondary to alcohol abuse. Arthroplast Today 2018;5:172-5.

5. Tripodi A, Mannucci PM. The coagulopathy of chronic liver disease. N Engl J Med 2011;365:147-56.

6. Huang HH, Lin HH, Shih YL, et al. Spontaneous intracranial hemorrhage in cirrhotic patients. Clin Neurol Neurosurg 2008;110:253-8.

7. Rahi MS, Pednekar P, Parmar G, et al. Spontaneous intercostal artery bleeding in a patient with alcoholinduced liver cirrhosis. Clin Case Rep 2021;9:e04613.

8. Salem RO, Laposata M. Effects of alcohol on hemostasis. Am J Clin Pathol 2005;123 Suppl:S96-105.

9. Yamashita S, Tanaka N, Nomura Y, et al. Iliopsoas muscle hematoma secondary to alcoholic liver cirrhosis. Case Rep Gastroenterol 2012;6:704-11.

10. Guerado E, Caso E. The physiopathology of avascular necrosis of the femoral head: an update. Injury 2016;47 Suppl 6:S16-26.

11. Zacharia GS, Ray R, Sivaprasad P, et al. Muscle hematomas: uncommon but horrendous complication of cirrhosis liver. Indian J Gastroenterol 2014;33:289-91. 